\title{
Cranial MRI diagnosis
}

\section{S K Misser, MB ChB, FCRad (D)}

Lake Smit and Partners, Durban

\section{Presentation}

A 50-year-old woman, known to have been recently diagnosed with advanced colonic carcinoma, and on palliative therapy, presented with an acute confusional state and associated seizures. The following MRI images were obtained.

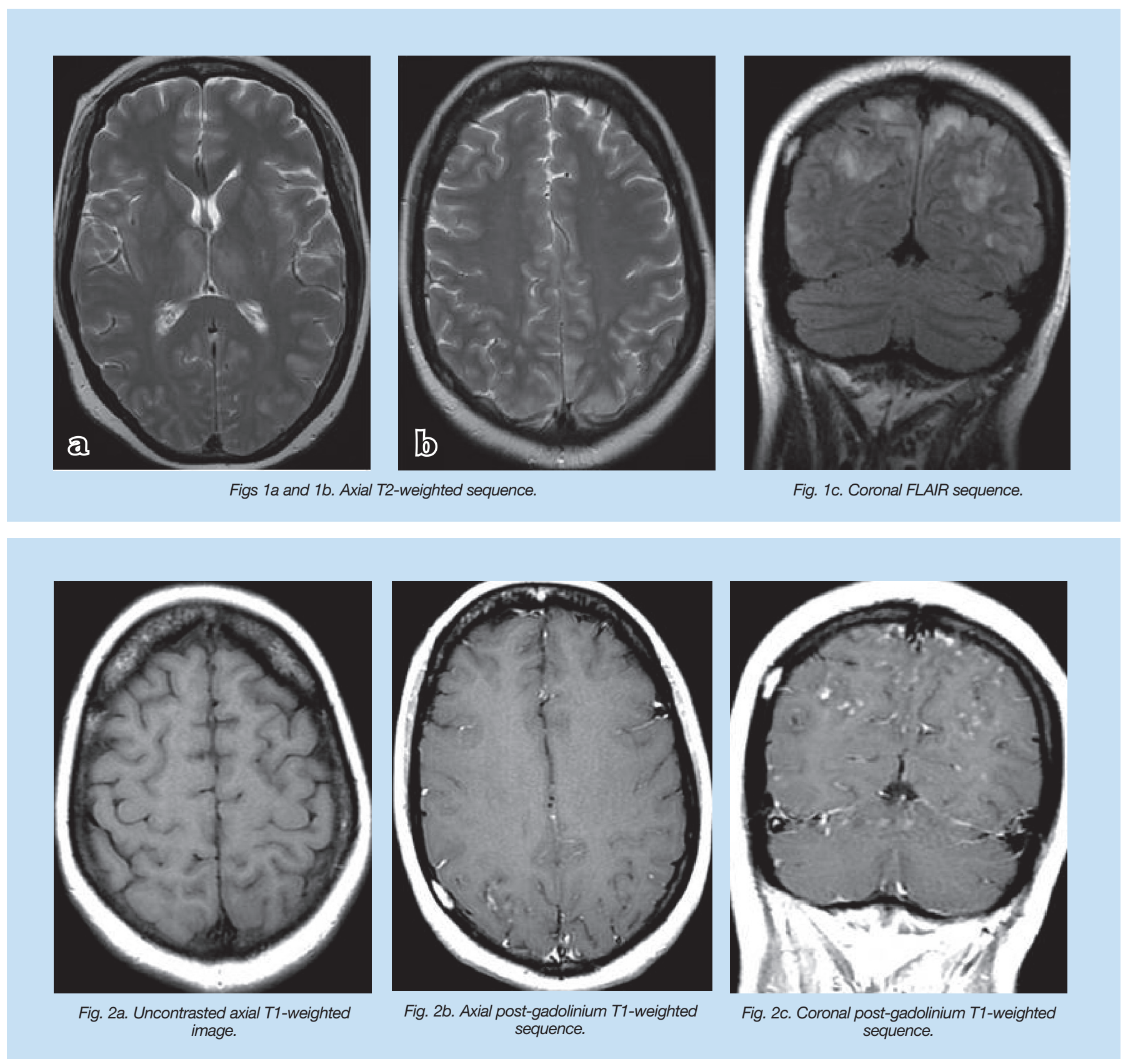

We invite readers to describe the MRI findings and provide the most appropriate clinical diagnosis. Please submit your response to shalendramisser@ hotmail.com. An award of R1 000 will be made for the best interpretation. A detailed diagnosis will be presented in the next SAJR. 